\title{
Dental and facial characteristics of osteogenesis imperfecta type V
}

3 Jean-Marc Retrouvey ${ }^{1 *}$, Doaa Taqi ${ }^{1}$, Faleh Tamimi ${ }^{1}$, Didem Dagdeviren ${ }^{1}$, Francis H. Glorieux ${ }^{2}$, Brendan

4 Lee $^{3}$, Renna Hazboun ${ }^{4}$, Deborah Krakow ${ }^{5}$, V. Reid Sutton ${ }^{3}$, Members of the BBD Consortium*, Frank 5 Rauch $^{2}$

6

$7 \quad{ }^{1}$ Faculty of Dentistry, McGill University, Montreal, Quebec, Canada

$8{ }^{2}$ Shriners Hospital for Children and McGill University, Montreal, Quebec, Canada

$9{ }^{3}$ Department of Molecular and Human Genetics, Baylor College of Medicine, Houston, TX, USA

$10 \quad{ }^{4}$ UCLA School of Dentistry, Los Angeles, CA, USA

$11{ }^{5}$ Department of Orthopedic Surgery, David Geffen School of Medicine, University of California, Los 12 Angeles, Los Angeles, CA, USA

14 *Correspondence author:

15 jean-marc.retrouvey@mcgill.ca (JMR)

17 Membership of the BBD Consortium is provided in the Acknowledgments. 


\section{Abstract}

Osteogenesis imperfecta (OI) type V is an ultrarare heritable bone disorder caused by the heterozygous c.-14C > T mutation in IFITM5. The dental and craniofacial phenotype has not been described in detail. In the present multicenter study (Brittle Bone Disease Consortium) 14 individuals with OI type V (age 3 to 50 years; 10 females, 4 males) underwent dental and craniofacial assessment. None of the individuals had dentinogenesis imperfecta. Six of the 9 study participants $(66 \%)$ for whom panoramic radiographs were obtained had at least one missing tooth (range 1 to 9). Class II molar occlusion was present in 8 (57\%) of the 14 study participants. The facial profile was retrusive and lower face height was decreased in $8(57 \%)$ individuals. Cephalometry, performed in three study participants, revealed a severely retrusive maxilla and mandible, and poorly angulated incisors in a 14-year old girl, a protrusive maxilla and a retrusive mandible in a 14-year old boy. Cone beam computed tomograpy scans were obtained from two study participants and demonstrated intervertebral disc calcification at the C2-C3 level in one individual. Our study observed that $\mathrm{OI}$ type $\mathrm{V}$ is associated with missing permanent teeth, especially permanent premolar, but not with dentinogenesis imperfecta. The pattern of craniofacial abnormalities in

OI type $\mathrm{V}$ thus differs from that in other severe OI types, such as OI type III and IV, and could be described as a bimaxillary retrusive malocclusion with reduced lower face height and multiple missing teeth. 


\section{Introduction}

Osteogenesis imperfecta (OI) is a heritable connective tissue disorder that is associated with bone variants in COL1A1 and COL1A2, the genes encoding collagen type I alpha chains (2). Clinically, such patients are classified into OI types I (least severe form), OI type II (perinatal lethal), OI type III (severe), OI type IV (moderate severity). There is presently no cure for OI, but bisphosphonate drugs are widely administered to increase bone density and decrease the number of fractures (1). Apart from fractures in long bones and vertebra, individuals with COL1A1- and COL1A2-related OI often have dental and craniofacial abnormalities, including dentinogenesis imperfecta (DI), tooth agenesis and malocclusion (3-5).

Among OI types not caused by COL1A1 or COL1A2, OI type $\mathrm{V}$ is the most prevalent disorder (6). OI type $\mathrm{V}$ is caused by the recurrent heterozygous c.-14C>T variant in IFITM5, which encodes BRIL, a transmembrane protein with unknown function that is specifically expressed in osteoblasts (7-9). The variant creates a new translational start site and leads to the addition of 5 amino acids at the N-terminus of the BRIL protein. OI type $\mathrm{V}$ resembles OI type IV with regard to fracture incidence, long-bone deformities, vertebral compression fractures and scoliosis $(10,11)$, but also has distinguishing features such as hyperplastic callus formation and calcification of the interosseous forearm membrane $(10,12)$. How the addition of 5 amino acids to BRIL protein leads to bone fragility is unknown at present. Mouse models harboring the OI type V variant die at birth, which complicates mechanistic studies $(13,14)$. Although OI type V seems to lead to similar bone material abnormalities and bone fragility as OI type IV caused by COL1A1/COL1A2 mutations $(10,15)$, little is known about the involvement of the 
62 eruption of the molars have been reported (17). A prospective, detailed characterization of the

63 craniofacial and dental phenotype in a cohort of OI type V has not been performed.

64 In the present report we therefore evaluated the dental and craniofacial characteristics in a cohort of

65 individuals with OI type $\mathrm{V}$ who were identified through the Brittle Bone Disease Consortium, a multicenter Rare Disease Clinical Research Network.

67

\section{Materials and Methods}

Study Participants

70 Individuals with a diagnosis of OI type V were recruited through the Brittle Bone Disease Consortium

71 (https://www.rarediseasesnetwork.org/cms/BBD) that comprises several specialized centers from across

72 North America (Houston, Montreal, Chicago, Baltimore, Portland, Washington DC, New York, Omaha,

73 Los Angeles). One of the projects conducted by the consortium is a natural history study to assess the

74 clinical features of OI. Patients with a diagnosis of OI of any type and any age are eligible to participate.

75 Dental evaluation is offered to participants who are three years of age or older.

76 The present study analyzes baseline dental data from the 14 study participants (10 females, 4 males; age

77 range 3 to 50 years) who had a diagnosis of OI type V. Two individuals in addition agreed to participate

78 in an ancillary study involving cone beam computed tomography (CBCT). For 11 individuals, the

79 diagnosis of OI type $\mathrm{V}$ was confirmed by genetic testing (heterozygosity for the c. $-14 \mathrm{C}>\mathrm{T}$ variant in

80 IFITM5); in 3 participants the diagnosis was based on clinical findings alone. Three cephalometric

81 radiographs were also studied. The study was approved at all participating study centers, and all study

82 participants or their legal guardians provided informed consent. 


\section{Craniofacial and dental evaluations}

85 The dental evaluation comprised clinical examination and extra- and intraoral photographs for all study participants, panoramic radiographs for those participants aged six years and older who consented to the test. The study dentist at each site performed the intraoral clinical examination and was responsible for obtaining a standard set of intraoral and extraoral photographs as well as panoramic radiographs. Examiners had been calibrated by passing the simplified International Caries Detection and Assessment System (ICDAS) examination (18). The photographs and radiographs were uploaded to the study website and were independently assessed by two experienced central readers, an orthodontist and an oral radiologist. There were no inter-observer disagreements on the assessments presented here. CBCT scans were evaluated by an oral and maxillofacial radiologist.

The clinical dental examination included assessing the classification of occlusion, overbite, overjet, crowding, open bite, crossbite, arch shape and the presence of DI (said to be present if at least one tooth appearing opalescent or had gray, brown or yellow color). The presence of DI was also assessed by examining panoramic radiographs (radiographic criteria for DI were: partial or complete pulp obliteration, bulbous crown, cervical constrictions, roots abnormalities or short root, and taurodontism).

Lateral and frontal photographs were used to assess facial type (normocephalic, brachycephalic or dolichocephalic; facial symmetry; facial proportions), and profile (normal, concave or convex), ear position (19), and frontal bossing. The facial type was determined by using the facial index that was calculated as the ratio between the maximum width to the maximum length of the face on the frontal photograph: dolichocephalic (long and narrow face), <0.72; normocephalic, 0.72 to 0.82 ; brachycephalic (short and wide face), >0.82 (20). Facial symmetry was determined by comparing the right and left sides of the face as determined by a reference midline passing through the glabella (midpoint between the eyebrow) and the subnasale points (the junction between the nasal septum and 
107 the upper lip). Facial proportions were calculated as follows: total face height, distance between glabella 108 and soft tissue pogonion (the most anteroinferior point of the chin); upper face height, distance between 109 glabella and subnasale; lower face height, distance between subnasale and the soft tissue pogonion. A 110 lower face height less than $47 \%$ of total face height was classified as reduced; a lower face height more 111 than $63 \%$ of total face height was classified as increased (21). Profile assessment was performed by 112 measuring the angle between glabella, subnasale, and soft tissue pogonion in a full profile picture. An 113 angle between 158 and 180 degrees was considered normal, regardless of sex (22). An angle <158 114 degrees indicates a convex profile while an angle $>180$ degree represents a flat to concave profile.

115 Lateral cephalometric radiographs were analyzed using the Ceph Tracing routine of the Dolphin 116 Imaging software package (version 11.8). Results were compared to normative cephalometric data as 117 published (23). CBCT scans were acquired with a 3D Accuitomo 170 (Morita Inc, Kyoto, Japan) CBCT was performed using Anatomage InVivo 5 version 5.4 (Invivo Dental; Anatomage, San Jose, CA) software.

122 In order to evaluate the projection of the lip and the convexity of the lower face, two measurements were used. The $\mathrm{H}$ angle measures the prominence of the lips in relation to the facial line (Nasion softpogonion soft: Normal mean value: 6 degrees, standard deviation 3 degrees) (24). The $\mathrm{Z}$ angle is used to measure facial balance and measures the prominence of the lips or the relative retrusiveness of the chin.

126 The $\mathrm{Z}$ angle is formed by the intersection of the lines $\mathrm{Na}$ (soft tissue)-Pogonion (soft tissue) and 127 Pogonion(soft tissue) - most prominent lip point. The normal mean for the $\mathrm{Z}$ angle is 10 degrees with a standard deviation of 4 degrees (25). 
129 Taking into account frequent reports of hypodontia in patients with OI, to evaluate the caries prevalence

130 in this population a modification of the DFT index was utilized. Wherein, caries scores were adjusted for

131 the missing teeth, by dividing the total sum of decayed and missing teeth by the total number of teeth

132 present in an individual. Therefore, this adjusted DFT is a continuous variable ranging from 0 to 1 , with

1330 being the minimum caries experience and 1 being the highest (26).

\section{Results}

136 Fourteen study participants with OI type V underwent dental evaluation (Table 1). Panoramic 137 radiographs were obtained in 9 study participants. None of the individuals had clinical or radiological 138 signs of DI. Tooth discoloration, pulp obliteration, bulbous crowns, short roots or taurodontism were not 139 observed in this cohort. Six of the nine study participants $(55 \%)$ for whom panoramic radiographs were 140 obtained had at least one missing tooth. The number of missing teeth ranged from 1 to 9 . Three of these 1419 individuals had retained deciduous teeth past the normal range of exfoliation; eight study participants 142 had impacted teeth. Ten study participants had an adjusted DFT score of 0 , in four subjects the adjusted 143 DFT score ranged from 0.21 to 0.67 . Examples of the clinical and radiological features are shown in $144 \quad$ Figures 1 and 2.

145 All study participants had normal ear position and no frontal bossing (Table 3). The facial profile was 146 retrusive in 8 of the 14 study participants (57\%). Assessment of facial proportions showed decreased 147 lower face height in 8 individuals (57\%).

148 Cephalometry was performed in three study participants (Figure 3). Individual 9, a 14-year old girl, 149 presented a severely retrusive maxilla and mandible, multiple missing teeth, an underdeveloped lower 150 face and poorly angulated upper and lower incisors. In contrast, individual 10, a 14-year old boy, had a 
151 protrusive maxilla and a retrusive mandible. Individual 13 presented with almost normal cephalometric 152 results.

153 CBCT scans were obtained from two study participants. An impacted upper second molar and the 154 absence of the lower third molars were detected in Individual 11 (not shown). In Individual 10, the 155 CBCT scan demonstrated impacted second molars and semi impacted lower first molars. An 156 intervertebral disc calcification at the C2-C3 level was also identified (Figure 4).

\section{Discussion}

159 In this largest dental and craniofacial study population reported to date, we found that DI was absent but that missing teeth, especially premolars was a common occurrence. Malocclusion associated with either 161 a retrusive maxilla or biretrusive jaws was also frequently observed. The facial type was either normal or 162 brachycephalic and more than half of the individuals with OI type V presented with a retrusive 163 (concave) profile and decreased lower face height due to underdeveloped maxillary and mandibular 164 dentoalveolar processes.

165 The absence of DI in OI type V has been reported in the first description of the disorder (10) and has 166 also been noted in subsequent case series $(16,17,27)$. This could be explained by the lack of a collagen 167 type I defect in OI type V, as collagen type I is the major protein of intertubular dentin (90\%) (28).

168 Previous reports have noted that missing teeth are a common finding in OI caused by COL1A1/COL1A2, 169 affecting the permanent dentition in $10 \%$ to $22 \%$ of individuals $(4,29)$. Premolars appear to be most 170 commonly affected (4). The present study suggests that premolars are also most frequently missing in OI

171 type V. Tooth development is a complex process involving signaling pathways that are also important 172 for skeletal development such as WNT signaling (30). It is therefore intuitive that genetic defects 
173 leading to major abnormalities in bone cell function also affect tooth development, but the precise 174 pathways whereby variants in IFITM5 lead to tooth agenesis are unknown at present.

175 Previous studies have shown a high prevalence of class III malocclusion in the more severe OI types 176 related to collagen type I mutations (OI types III and IV) $(29,31,32)$. These malocclusions are caused 177 by a severely hypoplastic maxilla and the counter rotation of the mandible resulting in severe negative 178 overjet. Cephalometric studies suggest that the relative mandibular prognathism in these OI types in part 179 reflects the decreased anterior length of the maxilla associated to a counterclockwise rotation of the mandible during growth (33). Our findings indicate that skeletal Class III malocclusion is less frequent in OI type V and that Class II malocclusion either of skeletal or dento alveolar origin is more frequent in OI type $\mathrm{V}$ than in other forms of moderate to severe OI. The severity of malocclusion varied widely in the present study independent of age. Six of the 14 study participants had severe malocclusion due to the presence of lateral open bite, multiple missing or impacted teeth and tooth migration. This indicates that their malocclusions presented significant therapeutic challenges where conventional orthodontic approaches would likely be inadequate. Nevertheless, the present study cohort presented with less severe malocclusion than what is typically seen in OI types III and IV caused by variants in COL1AI or COL1A2 (5).

Regarding facial characteristics, reduced lower face height and concave profile were more common in our study cohort, suggesting that the dentoalveolar processes do not develop normally but do not result in the severely prognathic profile that is often observed in individuals with OI type II and IV. Deficient dentoalveolar development may be due to missing teeth altering the growth or may be a direct effect of the IFITM5 variant.

194 In one of the two study participants who underwent CBCT scanning, we observed calcification of the 195 intervertebral disk at the C2-C3 level. Calcification of intervertebral discs is a rare condition in children, 
which may present with neck pain, limited neck movement or may be discovered incidentally as in the

present case. The cause of intervertebral disk calcification is unknown, but trauma and infection have been suggested as likely causes (34). Intervertebral disk calcification can lead to disc herniation, dysphagia or spinal cord compression (35), but can also resolve spontaneously (34). Thus, further follow-up of this individual will be important.

In conclusion, our study observed that OI type V is associated with missing teeth but not with DI. Facial analyses and cephalometric data show that $\mathrm{OI}$ type $\mathrm{V}$ is characterized by dentoalveolar alterations due to multiple missing teeth but not an exaggerated overjet, as is frequently observed in other types of OI. The malocclusion phenotype of OI type $\mathrm{V}$ varies widely, similar to the wide range of bone abnormalities found in the postcranial skeleton (16). The malocclusion of OI type V, if present, could be described as a biretrusive maxillomandibular malocclusion with reduced lower face height and multiple missing teeth.

OI type $\mathrm{V}$ thus is associated with a unique pattern of craniofacial abnormalities that differ considerably from the malocclusion of other forms of moderate to severe OI.

\section{Acknowledgements}

211 We are grateful to Jane Atkinson (National Institutes of Health) for helpful suggestions. This study was 212 performed as an activity of the Brittle Bone Disease Consortium. The Brittle Bone Disease Consortium 213 (1U54AR068069-0) is a National Center for Advancing Translational Sciences (NCATS) Rare Diseases 214 Clinical Research Network (RDCRN), and is funded through a collaboration between the Office of Rare 215 Diseases Research (ORDR), NCATS, the National Institute of Arthritis and Musculoskeletal and Skin 216 Diseases (NIAMS), and the National Institute of Dental and Craniofacial Research (NIDCR). The 217 content is solely the responsibility of the authors and does not necessarily represent the official views of 
218 the National Institutes of Health. The study was also supported by the Shriners of North America. None 219 of the authors declares a conflict of interest.

220 Members of the Brittle Bone Disease Consortium: Michael Bober ${ }^{6}$, Paul Esposito ${ }^{7}$, David R Eyre ${ }^{8}$, 221 Danielle Gomez ${ }^{9}$, Gerald Harris ${ }^{10}$, Tracy Hart ${ }^{11}$, Mahim Jain ${ }^{2}$, Jeffrey Krisher ${ }^{12}$, Sandesh CS 222 Nagamani $^{2}$, Eric S Orwoll ${ }^{13}$, Cathleen L Raggio ${ }^{14}$, Eric Rush ${ }^{7}$, Peter $_{\text {Smith }}{ }^{10}$, Laura Tosi $^{15}$

2236 Division of Medical Genetics, Nemours/Alfred I. duPont Hospital for Children, Wilmington, 224 Delaware; ${ }^{7}$ University of Nebraska Medical Center, Omaha, NE; ${ }^{8}$ Department of Orthopedic and 225 Sports Medicine, University of Washington, Seattle, WA; ${ }^{9}$ Shriners Hospital for Children - Tampa, 226 Tampa, FL; ${ }^{10}$ Shriners Hospital for Children - Chicago, Chicago, IL; ${ }^{11}$ Osteogenesis Imperfecta 227 Foundation, Gaithersburg, MD; ${ }^{12}$ Health Informatics Institute, Morsani College of Medicine, University 228 of South Florida, Tampa, FL; ${ }^{13}$ Department of Medicine, Division of Endocrinology, Oregon Health 229 Sciences University, Portland, OR; ${ }^{14}$ Hospital for Special Surgery, New York, NY; ${ }^{15}$ Bone Health 230 Program, Children's National Health System, Washington, DC, USA 


\section{References}

233 1. Trejo P, Rauch F. Osteogenesis imperfecta in children and adolescents-new developments in 234 diagnosis and treatment. Osteoporos Int 2016;27:3427-37.

235 2. Forlino A, Marini JC. Osteogenesis imperfecta. Lancet 2016;387:1657-71.

236 3. Andersson K, Dahllof G, Lindahl K, Kindmark A, Grigelioniene G, Astrom E, Malmgren B.

237 Mutations in COL1A1 and COL1A2 and dental aberrations in children and adolescents with

238 osteogenesis imperfecta - A retrospective cohort study. PLoS One 2017;12:e0176466.

239 4. Malmgren B, Andersson K, Lindahl K, Kindmark A, Grigelioniene G, Zachariadis V, Dahllof G, 240 Astrom E. Tooth agenesis in osteogenesis imperfecta related to mutations in the collagen type I genes.

241 Oral Dis 2017;23:42-9.

242 5. Rizkallah J, Schwartz S, Rauch F, Glorieux F, Vu DD, Muller K, Retrouvey JM. Evaluation of 243 the severity of malocclusions in children affected by osteogenesis imperfecta with the peer assessment 244 rating and discrepancy indexes. Am J Orthod Dentofacial Orthop 2013;143:336-41.

245 6. Bardai G, Moffatt P, Glorieux FH, Rauch F. DNA sequence analysis in 598 individuals with a 246 clinical diagnosis of osteogenesis imperfecta: diagnostic yield and mutation spectrum. Osteoporos Int $247 \quad 2016 ; 27: 3607-13$.

248 7. Semler O, et al. A mutation in the 5'-UTR of IFITM5 creates an in-frame start codon and causes 249 autosomal-dominant osteogenesis imperfecta type V with hyperplastic callus. Am J Hum Genet $250 \quad 2012 ; 91: 349-57$.

251 8. Cho TJ, et al. A single recurrent mutation in the 5'-UTR of IFITM5 causes osteogenesis 252 imperfecta type V. Am J Hum Genet 2012;91:343-8.

253 9. Moffatt P, et al. Bril: a novel bone-specific modulator of mineralization. J Bone Miner Res $254 \quad 2008 ; 23: 1497-508$. 
255 10. Glorieux FH, et al. Type V osteogenesis imperfecta: a new form of brittle bone disease. J Bone 256 Miner Res 2000;15:1650-8.

257 11. Zeitlin L, Rauch F, Travers R, Munns C, Glorieux FH. The effect of cyclical intravenous 258 pamidronate in children and adolescents with osteogenesis imperfecta Type V. Bone 2006;38:13-20.

259 12. Cheung MS, Glorieux FH, Rauch F. Natural history of hyperplastic callus formation in 260 osteogenesis imperfecta type V. J Bone Miner Res 2007;22:1181-6.

261 13. Lietman CD, et al. A transgenic mouse model of OI type V supports a neomorphic mechanism of 262 the IFITM5 mutation. J Bone Miner Res 2015;30:489-98.

263 14. Rauch F, Geng Y, Lamplugh L, Hekmatnejad B, Gaumond MH, Penney J, Yamanaka Y, Moffatt 264 P. Crispr-Cas9 engineered osteogenesis imperfecta type V leads to severe skeletal deformities and 265 perinatal lethality in mice. Bone 2018;107:131-42.

266 15. Blouin S, Fratzl-Zelman N, Glorieux FH, Roschger P, Klaushofer K, Marini JC, Rauch F. Bone 267 matrix hypermineralization and increased osteocyte lacunae density in patients with osteogenesis 268 imperfecta type V. J Bone Miner Res 2017;32:1884-92.

269 16. Rauch F, et al. Osteogenesis imperfecta type V: marked phenotypic variability despite the 270 presence of the IFITM5 c.-14C>T mutation in all patients. J Med Genet 2013;50:21-4.

271 17. Kim $\mathrm{OH}$, et al. Osteogenesis imperfecta type V: clinical and radiographic manifestations in 272 mutation confirmed patients. Am J Med Genet A 2013;161a:1972-9.

273 18. Gugnani N, Pandit IK, Srivastava N, Gupta M, Sharma M. International Caries Detection and 274 Assessment System (ICDAS): A New Concept. Int J Clin Pediatr Dent 2011;4:93-100.

275 19. Farkas LG. Vertical location of the ear, assessed by the Leiber test, in healthy North American 276 Caucasians 6--19 years of age. Arch Otorhinolaryngol 1978;220:9-13. 
277 20. Franco FC, de Araujo TM, Vogel CJ, Quintao CC. Brachycephalic, dolichocephalic and

278 mesocephalic: Is it appropriate to describe the face using skull patterns? Dental Press J Orthod

$279 \quad 2013 ; 18: 159-63$.

280 21. Nanda SK. Patterns of vertical growth in the face. Am J Orthod Dentofacial Orthop

$281 \quad 1988 ; 93: 103-16$.

282 22. Anic-Milosevic S, Lapter-Varga M, Slaj M. Analysis of the soft tissue facial profile by means of 283 angular measurements. Eur J Orthod 2008;30:135-40.

284 23. Jacobson A, Jacobson RL. Radiographic cephalometry: From basics to 3-D imaging, 2nd edition: 285 Quintessence Publishing Company; 2007.

286 24. Holdaway RA. A soft-tissue cephalometric analysis and its use in orthodontic treatment 287 planning. Part I. Am J Orthod 1983;84:1-28.

288 25. Merrifield LL. The profile line as an aid in critically evaluating facial esthetics. Am J Orthod $289 \quad 1966 ; 52: 804-22$.

290 26. Ulseth JO, Hestnes A, Stovner LJ, Storhaug K. Dental caries and periodontitis in persons with 291 Down syndrome. Special Care in Dentistry 1991;11:71-3.

292 27. Brizola E, Mattos EP, Ferrari J, Freire PO, Germer R, Llerena JC, Jr., Felix TM. Clinical and 293 molecular characterization of osteogenesis imperfecta type V. Mol Syndromol 2015;6:164-72.

294 28. Goldberg M, Kulkarni AB, Young M, Boskey A. Dentin: structure, composition and 295 mineralization. Front Biosci (Elite Ed) 2011;3:711-35.

296 29. O'Connell AC, Marini JC. Evaluation of oral problems in an osteogenesis imperfecta population. 297 Oral Surg Oral Med Oral Pathol Oral Radiol Endod 1999;87:189-96.

298 30. Juuri E, Balic A. The biology underlying abnormalities of tooth number in humans. J Dent Res $299 \quad 2017 ; 96: 1248-56$. 
300 31. Schwartz S, Tsipouras P. Oral findings in osteogenesis imperfecta. Oral Surg Oral Med Oral $301 \quad$ Pathol 1984;57:161-7.

302 32. Chang PC, Lin SY, Hsu KH. The craniofacial characteristics of osteogenesis imperfecta patients. 303 Eur J Orthod 2007;29:232-7.

304 33. Waltimo-Siren J, Kolkka M, Pynnonen S, Kuurila K, Kaitila I, Kovero O. Craniofacial features 305 in osteogenesis imperfecta: a cephalometric study. Am J Med Genet A 2005;133:142-50.

306 34. Dai LY, Ye H, Qian QR. The natural history of cervical disc calcification in children. J Bone 307 Joint Surg Am 2004;86-a:1467-72.

308 35. Mohanty S, Sutter B, Mokry M, Ascher PW. Herniation of calcified cervical intervertebral disk 309 in children. Surg Neurol 1992;38:407-10. 


\section{Figure Legends}

Figure 1. OI type V, Individual 9 (girl, 14 years). A, B. Intraoral photographs, showing posterior open bite, and Class III malocclusion. C, D. Occlusal view, showing missing premolars and retained lower deciduous molars. E. Panoramic radiograph, showing the deciduous molars with resorbed roots, unerupted $2^{\text {nd }}$ molar (arrows), a missing lower incisor and the position of the 8 missing premolars

317 (asterisks). Third molars are also congenitally missing (asterisks).

Figure 2. Individual 4 (girl, 8 years). A, B, C Intra-oral photographs, showing the anterior open bite with Class II malocclusion due to migration of upper permanent molars. D. Occlusal plane view. The radiograph shows the agenesis of the premolars $(15,25,44,34)$ as well as multiple impactions $(12,13$, $14,24)$.

Figure 3. Cephalograms A, B. Individual 9 (girl, 14 years). The maxilla and mandible are significantly retrognathic. The ANB angle (-6.7 degrees, corresponding to 4.9 standard deviations [SD] below the reference mean value) and the Wits measurements (the length in mm of the yellow lines on the occlusal plane; $8.0 \mathrm{~mm}$ [3.1 SD above the reference mean value]) are abnormal, indicating a Class III biretrusive skeletal malocclusion compensated by severely proclined upper incisors ( 1 to NA line: 42.8 degrees; norm: 11 to 35 degrees) and severely retroclined lower incisors (lower incisor to mandibular plane angle: 67.8 degrees, norm: 83.4 to 99.4 degrees). The mandibular plane angle is also significantly decreased (15 degrees, norm: 25 to 41 degrees) indicating a severely brachycephalic facial type. retrognathic (the SNB angle is 74 degrees, reference mean 78 [SD: 3.0] degrees). The maxilla- 
334 mandibular relationship is abnormal (the ANB angle is 7.4 degrees, reference mean 3.0 (SD: 2.0) 335 degrees; Wits is 7.3, reference mean 2.0 [SD: 2.0] mm). All four second molars are impacted, the lower 336 right first molar is semi-impacted and has only erupted partially. Roots on the lower left first molar are 337 shortened. Typical Class II division 1 malocclusion with a retrognathic mandible and a reduced lower 338 face height.

339 E, F. Individual 13 (47 year old male). Almost normal cephalometric measurements.

341 Figure 4. Cone Beam CT of Individual 10 (boy, 14 years). A. Three-dimensional volume rendering 342 image. An unusual prognathic maxilla, impacted second molars (*) and lower right first molar is semi343 impacted (arrowhead). B. Sagittal and C. Coronal images. There is a well-defined, round shaped 344 radiopaque entity within the disc space at the $\mathrm{C} 2-\mathrm{C} 3$ level, consistent with intervertebral disc 345 calcification (arrow). The adjacent vertebral end plates appear normal. 
Table 1. General clinical information and dental evaluation.

\begin{tabular}{|c|c|c|c|c|c|c|c|}
\hline $\begin{array}{l}\text { Indi- } \\
\text { vidual }\end{array}$ & Sex & $\begin{array}{l}\text { Age } \\
\text { (yrs) }\end{array}$ & $\begin{array}{l}\text { Pan- } \\
\text { orex }\end{array}$ & Missing teeth & $\begin{array}{c}\text { Retained } \\
\text { teeth }\end{array}$ & Impacted teeth & DFT \\
\hline 1 & $\mathrm{f}$ & 3 & No & n.a. & n.a. & n.a. & 0 \\
\hline 2 & $\mathrm{f}$ & 4 & No & n.a. & n.a. & n.a. & 0 \\
\hline 3 & $\mathrm{f}$ & 7 & No & n.a. & n.a. & n.a. & 0 \\
\hline 4 & $\mathrm{f}$ & 8 & Yes & $15,25,34,44$ & none & $12,13,14,24$ & 0.21 \\
\hline 5 & $\mathrm{~m}$ & 8 & No & n.a. & n.a. & n.a. & 0 \\
\hline 6 & $\mathrm{f}$ & 11 & Yes & $\begin{array}{c}15,24,25,31, \\
34,35,41,44,45\end{array}$ & $\begin{array}{c}55,73,74,83, \\
84 \\
\end{array}$ & 14 & 0 \\
\hline 7 & $\mathrm{f}$ & 14 & Yes & none & none & none & 0.58 \\
\hline 8 & $\mathrm{f}$ & 14 & Yes & none & none & 17 & 0 \\
\hline 9 & $\mathrm{f}$ & 14 & Yes & $\begin{array}{c}14,15,24,25, \\
34,35,41,44,45\end{array}$ & 75,85 & $17,27,37,47$ & 0 \\
\hline 10 & $\mathrm{~m}$ & 14 & Yes & none & none & $17,27,37,46,47$ & 0 \\
\hline 11 & $\mathrm{f}$ & 18 & Yes & 38,48 & none & 17 & 0 \\
\hline 12 & $\mathrm{f}$ & 41 & Yes & $15,25,34,35,45$ & none & 27 & 0 \\
\hline 13 & $\mathrm{~m}$ & 47 & Yes & 35 & none & $28,38,48$ & 0.67 \\
\hline 14 & $\mathrm{~m}$ & 50 & No & Not available & none & none & 0.40 \\
\hline
\end{tabular}

Abbreviations: n.a., not available; DFT, decayed and filled teeth 
Table 2. Occlusion data.

\begin{tabular}{|c|c|c|c|c|c|c|c|c|c|c|c|c|}
\hline $\begin{array}{l}\text { Indi- } \\
\text { vidual }\end{array}$ & $\begin{array}{l}\text { Molar } \\
\text { occl } \\
\text { right }\end{array}$ & $\begin{array}{c}\text { Molar } \\
\text { occl } \\
\text { left }\end{array}$ & $\begin{array}{c}\text { Canine } \\
\text { occl } \\
\text { right }\end{array}$ & $\begin{array}{c}\text { Canine } \\
\text { occl } \\
\text { left }\end{array}$ & $\begin{array}{l}\text { Severity } \\
\text { of mal- } \\
\text { occlusion }\end{array}$ & $\begin{array}{c}\text { Over- } \\
\text { jet } \\
(\mathbf{m m})\end{array}$ & $\begin{array}{c}\text { Over- } \\
\text { bite }(\%)\end{array}$ & $\begin{array}{c}\text { Anterior } \\
\text { cross- } \\
\text { bite }\end{array}$ & $\begin{array}{c}\text { Posterior } \\
\text { cross- } \\
\text { bite }\end{array}$ & $\begin{array}{c}\text { Anterior } \\
\text { open } \\
\text { bite }\end{array}$ & $\begin{array}{c}\text { Lateral } \\
\text { open } \\
\text { bite } \\
\end{array}$ & $\begin{array}{c}\text { Crow- } \\
\text { ding }\end{array}$ \\
\hline 1 & I & II & II & II & Mild & 2 & 15 & $\mathrm{y}$ & $\mathrm{y}$ & $\mathrm{n}$ & $\mathrm{y}$ & mild \\
\hline 2 & II & I & II & I & severe & 0 & Openbite & $\mathrm{y}$ & $\mathrm{y}$ & $\mathrm{y}$ & $\mathrm{y}$ & $\mathrm{n}$ \\
\hline 3 & I & I & I & I & mild & 1 & 0 & $\mathrm{n}$ & $\mathrm{n}$ & $\mathrm{n}$ & $\mathrm{n}$ & $\mathrm{n}$ \\
\hline 4 & II & II & n.a. & n.a. & severe & -2 & Openbite & $\mathrm{y}$ & $\mathrm{y}$ & $\mathrm{y}$ & $\mathrm{n}$ & mild \\
\hline 5 & II & II & n.a. & I & mild & 0 & Openbite & $\mathrm{y}$ & $\mathrm{n}$ & $\mathrm{y}$ & $\mathrm{n}$ & mild \\
\hline 6 & II & II & n.a. & n.a. & severe & 4 & 100 & $\mathrm{n}$ & $\mathrm{y}$ & $\mathrm{n}$ & $\mathrm{n}$ & $\mathrm{n}$ \\
\hline 7 & I & I & I & I & mild & 2 & 10 & $\mathrm{n}$ & $\mathrm{n}$ & $\mathrm{n}$ & $\mathrm{n}$ & $\mathrm{n}$ \\
\hline 8 & II & II & II & II & moderate & 0 & Openbite & $\mathrm{y}$ & $\mathrm{y}$ & $\mathrm{y}$ & $\mathrm{n}$ & $\mathrm{n}$ \\
\hline 9 & II & II & III & III & severe & -1 & 0 & $\mathrm{y}$ & $\mathrm{y}$ & $\mathrm{y}$ & $\mathrm{y}$ & $\mathrm{n}$ \\
\hline 10 & II & II & II & II & severe & 6 & 40 & $\mathrm{n}$ & $\mathrm{n}$ & $\mathrm{n}$ & $\mathrm{n}$ & mild \\
\hline 11 & I & I & I & I & $\begin{array}{c}\text { n.a. } \\
\text { (braces) }\end{array}$ & 2 & 25 & $\mathrm{n}$ & $\mathrm{n}$ & $\mathrm{n}$ & $\mathrm{n}$ & $\mathrm{n}$ \\
\hline 12 & I & $\mathrm{I}$ & I & $\mathrm{I}$ & moderate & 2 & 75 & $\mathrm{n}$ & $\mathrm{n}$ & $\mathrm{n}$ & $\mathrm{n}$ & moderate \\
\hline 13 & $\mathrm{I}$ & III & I & II & severe & 0 & Openbite & $\mathrm{y}$ & $\mathrm{y}$ & $\mathrm{y}$ & $\mathrm{y}$ & $\mathrm{n}$ \\
\hline 14 & III & III & III & II & mild & 2 & 25 & $\mathrm{n}$ & $\mathrm{y}$ & $\mathrm{n}$ & $\mathrm{y}$ & mild \\
\hline
\end{tabular}

Abbreviation: n, no; n.a., not available; occl, occlusion; y, yes 
Table 3. Facial characteristics.

\begin{tabular}{|c|c|c|c|c|c|c|}
\hline $\begin{array}{c}\text { Indi- } \\
\text { vidual }\end{array}$ & $\begin{array}{c}\text { Face } \\
\text { Type }\end{array}$ & $\begin{array}{c}\text { Facial } \\
\text { Profile }\end{array}$ & H line & $\mathbf{Z}$ angle & $\begin{array}{c}\text { Facial } \\
\text { Proportions }\end{array}$ & $\begin{array}{c}\text { Facial } \\
\text { Proportions (\%) }\end{array}$ \\
\hline 1 & brachy & retrusive & 7.8 & 76.9 & normal & 46 \\
\hline 2 & brachy & retrusive & $\mathrm{Na}$ & n.a & NA & na \\
\hline 3 & normo & normal & 19.1 & 70.4 & normal & 54 \\
\hline 4 & normo & retrusive & 10.8 & 71.3 & decreased LFH & 45 \\
\hline 5 & normo & normal & 24.5 & 59.3 & Normal & 52 \\
\hline 6 & brachy & retrusive & 24.7 & 56.8 & Normal & 53 \\
\hline 7 & brachy & retrusive & 3.7 & 78.3 & decreased LFH & 46 \\
\hline 8 & normo & normal & 20.8 & 76.4 & Normal & 50 \\
\hline 9 & brachy & retrusive & 0.1 & 91.8 & decreased LFH & 47 \\
\hline 10 & brachy & convex & 24.6 & 65.8 & decreased LFH & 43 \\
\hline 11 & brachy & retrusive & 11.2 & 76.8 & normal & 50 \\
\hline 12 & normo & retrusive & 1.4 & 86.6 & decreased LFH & 43 \\
\hline 13 & normo & normal & 6.1 & 88.6 & Normal & 47 \\
\hline 14 & normo & normal & 9.3 & 99.9 & normal & 52 \\
\hline
\end{tabular}

Abbreviations: LFH: lower face height; Normo: Normocephalic; Brachy: Brachycephalic 
Figure 1
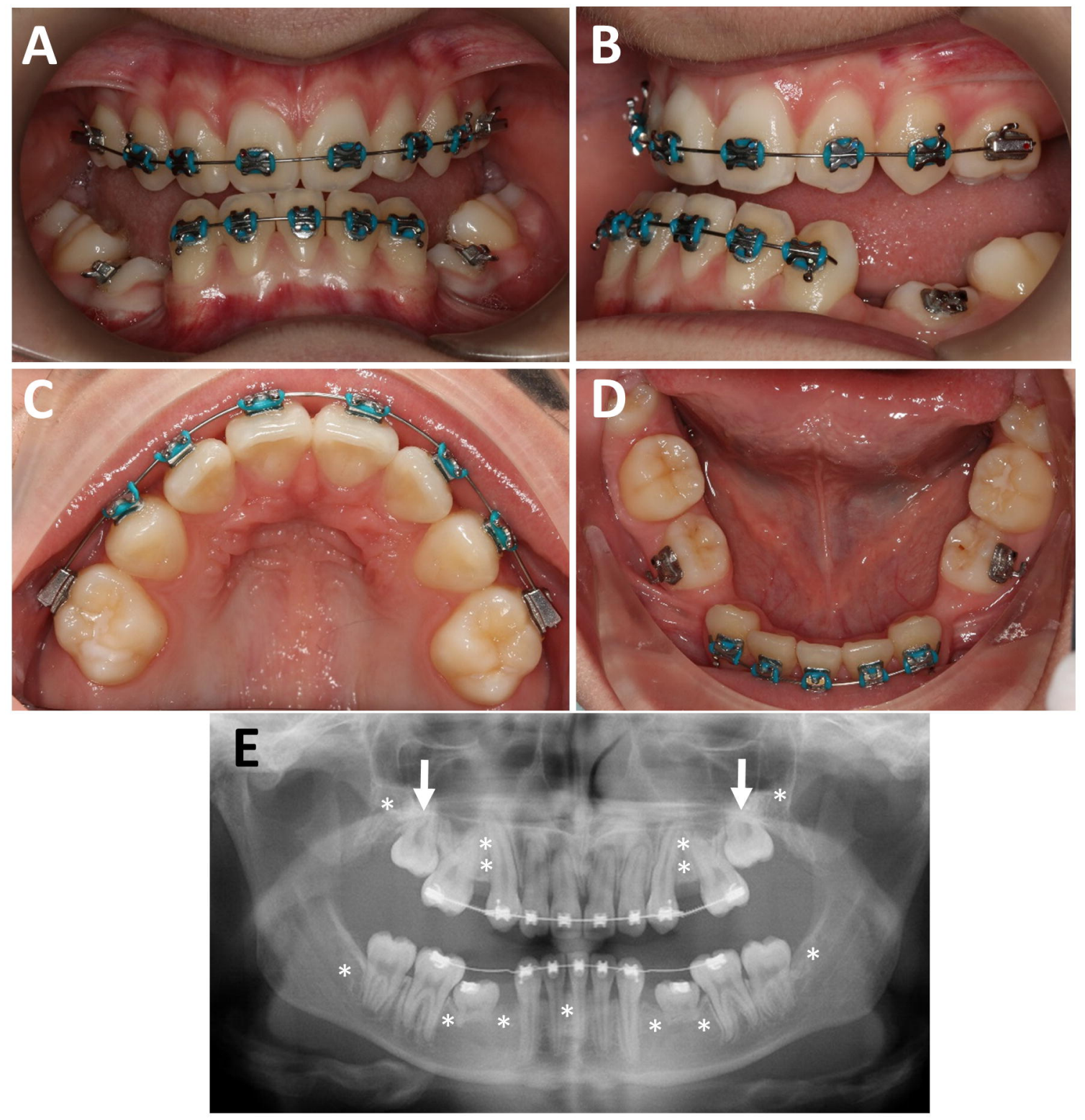
Figure 2
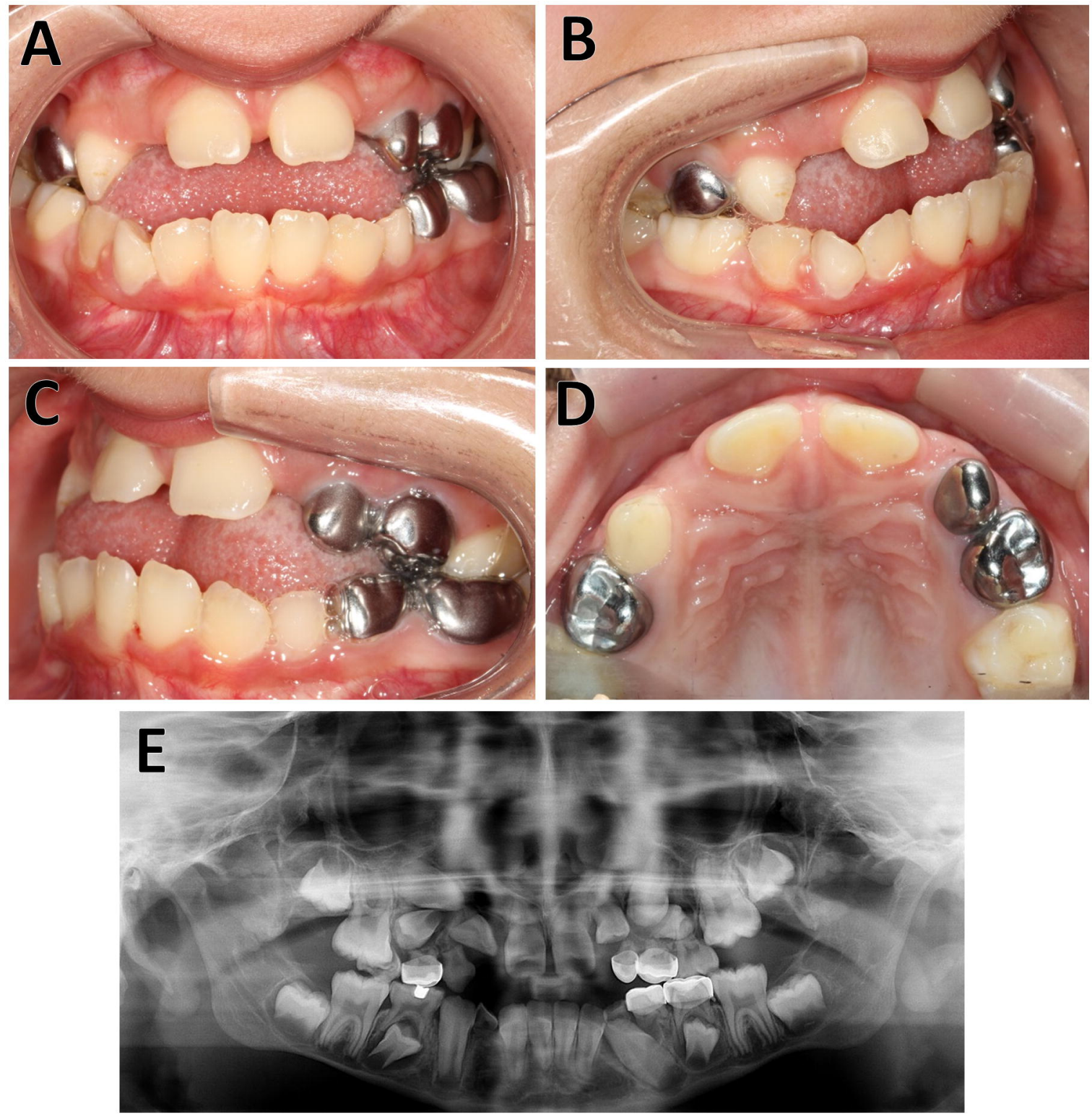
bioRxiv preprint doi: https://doi.org/10.1101/413633; this version posted September 11,2018 . The copyright holder for this preprint (which was not certified by peer review) is the author/funder. All rights reserved. No reuse allowed without permission.
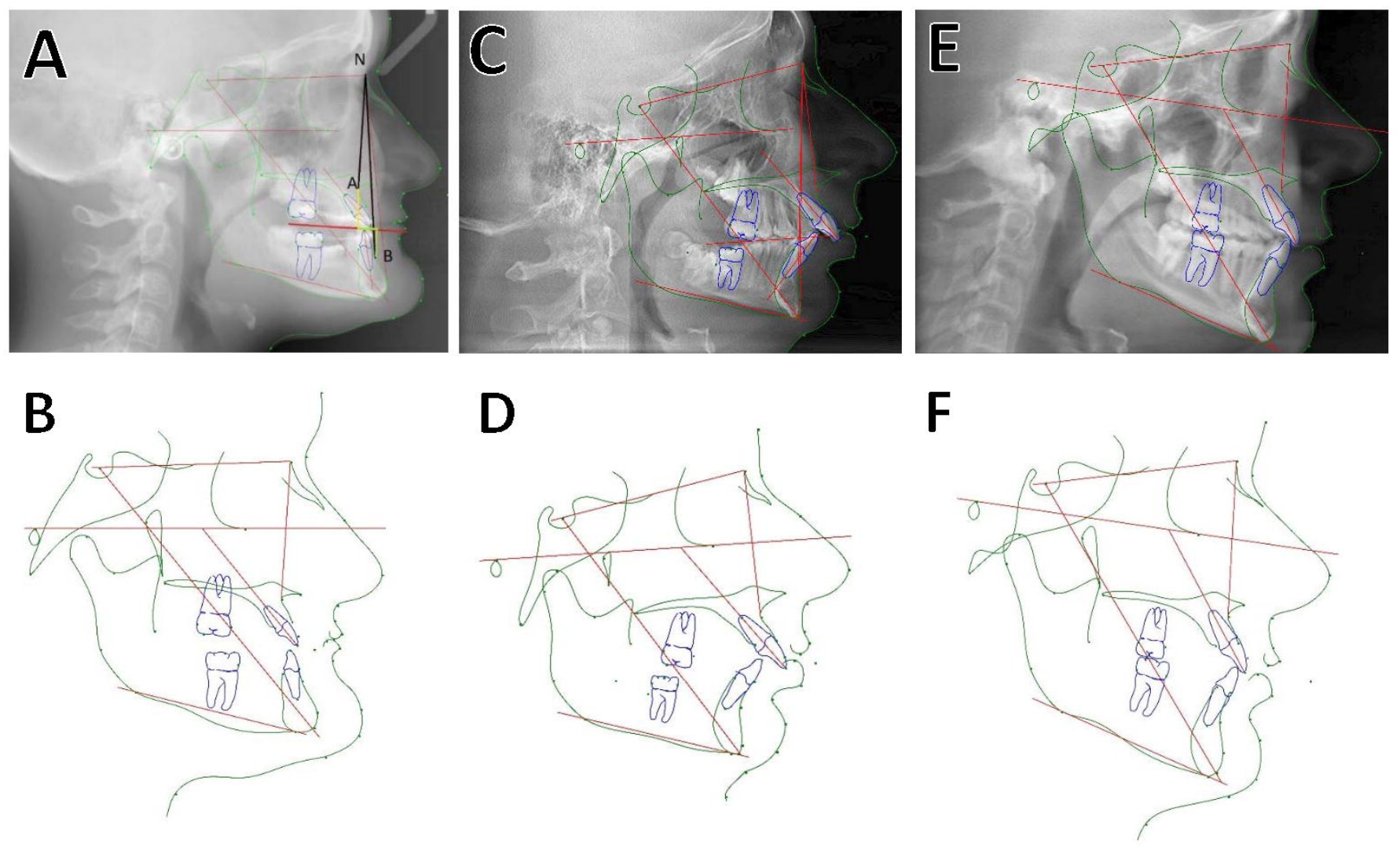
Figure 4
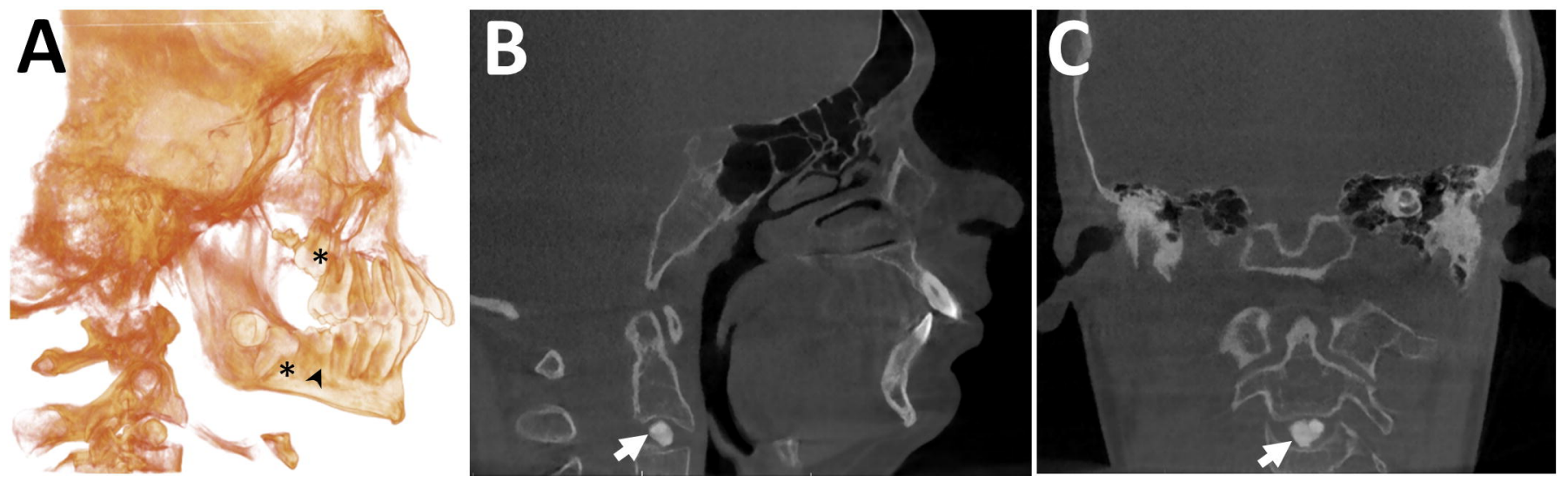